Check for updates

Cite this: RSC Adv., 2017, 7, 34567

\title{
Microcosmic understanding on thickening capability of copolymers in supercritical carbon dioxide: the key role of $\pi-\pi$ stacking
}

\author{
Wenchao Sun, (D) a Baojiang Sun, ${ }^{\text {aa }}$ Ying Li, ${ }^{\mathrm{b}}$ Haiming Fan, ${ }^{\mathrm{a}}$ Yonghai Gao, ${ }^{\mathrm{a}}$ \\ Haoyang Sun ${ }^{\mathrm{b}}$ and Guangchao $\mathrm{Li}^{\mathrm{c}}$
}

In this study, styrene/heptadecafluorodecyl acrylate (St-HFDA) copolymers of different compositions were synthetized for the purpose of thickening supercritical carbon dioxide $\left(\mathrm{SC}-\mathrm{CO}_{2}\right)$. The cloud point pressures of the copolymer- $\mathrm{CO}_{2}$ mixtures and the thickening effects of these copolymers for $\mathrm{SC}-\mathrm{CO}_{2}$ were measured. Molecular dynamics (MD) simulations were used to evaluate the intermolecular interactions and microstructures of polymer- $\mathrm{CO}_{2}$ systems, the copolymer- $\mathrm{CO}_{2}$ interaction energy, cohesive energy density (CED), solubility parameter, equilibrium conformations and radial distribution functions (RDFs) were obtained, which provided useful information for microscopic understanding on the thickening capability of copolymers in $\mathrm{SC}-\mathrm{CO}_{2}$. It was found that all the synthesized St-HFDA copolymers induced greater viscosity enhancements of $\mathrm{SC}-\mathrm{CO}_{2}$ compared to poly(Heptadecafluorodecyl acrylate) (PHFDA), and $\pi-\pi$ stacking of the Styrene (St) groups played a key role in thickening $\mathrm{SC}_{-} \mathrm{CO}_{2}$. On one hand, the introduction of the St groups into PHFDA weakened the $\mathrm{CO}_{2}$-philicity of the polymers by reducing the polymer- $\mathrm{CO}_{2}$ interaction and increasing polymer-polymer interactions, resulting in higher cloud point pressure in $\mathrm{SC}-\mathrm{CO}_{2}$ compared to PHFDA. On the other hand, the increase of the polymer-polymer interaction via $\pi-\pi$ stacking provided an associative force to thicken $\mathrm{SC}-\mathrm{CO}_{2}$. The subtle relationship between the copolymer composition and thickening abilities of the copolymers in $\mathrm{SC}-\mathrm{CO}_{2}$ were evaluated and the optimum styrene molar ratio was determined. It can be concluded that the content of the $\mathrm{CO}_{2}$-philic HFDA groups and the $\mathrm{CO}_{2}$-phobic St groups in the copolymers should be optimized to achieve the balance between the solubility and the thickening capability.

Received 31st May 2017

Accepted 4th July 2017

DOI: $10.1039 / c 7 r a 06041 f$

rsc.li/rsc-advances

\section{Introduction}

As a green solvent that is expected to replace the conventional organic solvents, supercritical carbon dioxide $\left(\mathrm{SC}^{-} \mathrm{CO}_{2}\right)$ has high potential in many industrial processes because of the mild critical temperature and pressure. In the oil and gas industry, $\mathrm{CO}_{2}$ is usually used in enhance oil recovery (EOR), and is considered as one type of clean fracturing fluid which is expected to replace the traditional water-based fracturing fluids. ${ }^{1-3}$ The primary disadvantage of $\mathrm{CO}_{2}$ which has limited its use in EOR is its bad spread efficiency due to the lower viscosity and the large mobility difference compared to oil..$^{4-6}$ As a fracturing fluid, one of the functions of $\mathrm{CO}_{2}$ is to transport proppants into reservoir fractures to support oil-gas pathway, so enhancing the

${ }^{a}$ School of Petroleum Engineering, China University of Petroleum, Qingdao, Shandong 266580, P. R. China. E-mail: sunbj1128@vip.126.com; Fax: +860532 86983137; Tel: +86053286981707

${ }^{b}$ Key Laboratory of Colloid and Interface Chemistry of Staten Education Ministry, Shandong University, Jinan, Shandong 250100, P. R. China

${ }^{c}$ Beijing Xingyou Project Management Co., Ltd, China National Petroleum Corporation, Beijing 100083, P. R. China viscosity of $\mathrm{CO}_{2}$ by adding thickening agents is an urgent challenge not only for increasing the spread efficiency but also for improving the proppant carrying capacity. ${ }^{7}$

However, the thickening of $\mathrm{CO}_{2}$ is difficult to achieve, because $\mathrm{CO}_{2}$ is a poor solvent for most polymers. ${ }^{8-10}$ Previous studies ${ }^{11-16}$ have showed that only silicone polymers and fluorinated polymers could be dissolved in $\mathrm{CO}_{2}$ under low pressure. In the $\mathrm{CO}_{2}$-polymer system, it is possible for the polymer to dissolve in $\mathrm{CO}_{2}$ when the polymer- $\mathrm{CO}_{2}$ interaction is greater than the polymer-polymer interaction. ${ }^{17,18}$ Thus, the strong polymer- $\mathrm{CO}_{2}$ interaction is the premise for the polymers being dissolved in $\mathrm{CO}_{2}$, and the weak polymer-polymer interaction is considered to be the basis of solvation. ${ }^{19-21}$ But on the other side, too weak polymer-polymer interaction is not favourable for increasing the viscosity of $\mathrm{CO}_{2}$ by intermolecular association. So the moderate polymer-polymer interaction is essential for polymer to dissolve in and thicken $\mathrm{CO}_{2}$.

According to the references in the literature, using copolymer obtained by copolymerizing the $\mathrm{CO}_{2}$-philic and $\mathrm{CO}_{2}{ }^{-}$ phobic monomers is an effective strategy to form viscosityenhancing molecular aggregates via $\pi-\pi$ stacking, hydrogen bond and van der Waals interactions. ${ }^{12,22-25}$ For instance, 
Beckman et al. have attempted to thicken liquid $\mathrm{CO}_{2}$ by StHFDA copolymers and obtained good results. ${ }^{4,7}$ But the investigations about the thickening mechanism are rare, let alone the intensive understanding from the microscopic view.

Computer simulation has provided new way to study the mechanism of intermolecular interactions in polymer- $\mathrm{CO}_{2}$ systems, and has been used to investigate the effects of microstructure variations on macroscopic properties. ${ }^{26-29}$ The most current report about simulations used for $\mathrm{CO}_{2}$-polymer systems are $a b$ initio quantum mechanical calculations for polymer repeat unit under absolute zero. But its calculation scale is too small to simulate systems containing large number of atoms. $^{30,31}$ Wang $^{26}$ has calculated the bonding modes and interaction energies between polymer repeat units and $\mathrm{CO}_{2}$ by $a b$ initio method, but the calculated results conflicted with the experimental results. Molecular dynamics simulation based on molecular mechanics could simulate the interaction of $\mathrm{CO}_{2}$ with polymer chains at actual temperatures and pressures, so its calculation results are more credible. ${ }^{17}$

This paper is devoted to the investigations for the influences of the intermolecular interactions on the thickening capability of copolymer in $\mathrm{SC}-\mathrm{CO}_{2}$. The study will help to reveal the thickening mechanism for $\mathrm{SC}-\mathrm{CO}_{2}$, and thereby provide design guidelines for the exploration of $\mathrm{SC}-\mathrm{CO}_{2}$ thickening agents. Four kinds of St-HFDA copolymers and PHFDA homopolymer were synthetized by free radical polymerization. The cloud point pressures and the thickening effects of these polymers in SC$\mathrm{CO}_{2}$ were measured. The relations of the copolymer compositions with the intermolecular interactions and thickening effects were investigated by combining MD simulations and experimental measurements. The MD simulation results of polymer- $\mathrm{CO}_{2}$ interaction energy, cohesive energy density (CED), solubility parameter, equilibrium conformations and radial distribution functions (RDFs) were used to evaluate the intermolecular interactions and microstructures of polymer- $\mathrm{CO}_{2}$ systems. The key role of $\pi-\pi$ stacking of the St groups in thickening $\mathrm{SC}-\mathrm{CO}_{2}$ and the optimum St molar ratio in copolymers were determined. The content optimization principle of the $\mathrm{CO}_{2}$-philic HFDA group and the $\mathrm{CO}_{2}$-phobic St group in the copolymers were explored.

\section{Methods}

\section{Copolymers synthesis and properties measurements}

$3,3,4,4,5,5,6,6,7,7,8,8,9,9,10,10,10$-Heptadecafluorodecyl acrylate (HFDA, 98\%, Alfa Aesar) and styrene (St, 99.5\%, Alfa Aesar) were used to synthesize the copolymers. 2,2'-Azobisisobutyronitrile (AIBN, 99\%) was purchased from Aldrich and purified twice by recrystallization from methanol. ${ }^{32}$ 1,1,2-Trichlorotrifluoroethane (99.5\%) and methanol (99.9\%) were obtained from Aldrich and used as purchased.

The styrene/heptadecafluorodecyl acrylate copolymer was synthesized with AIBN as initiator according to the procedure of Beckman et al., as shown in Scheme 1.,33,34 The mixture of $33.4 \mathrm{~g}$ HFDA and $6.6 \mathrm{~g}$ styrene was bubbled with nitrogen for 30 minutes to ensure that the entire reaction was under the nitrogen atmosphere. The reaction flask was sealed after adding

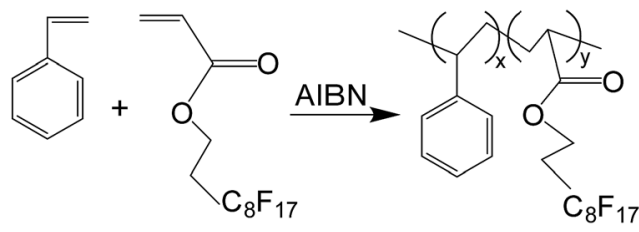

Scheme 1 Synthetic procedure of the St-HFDA copolymer.

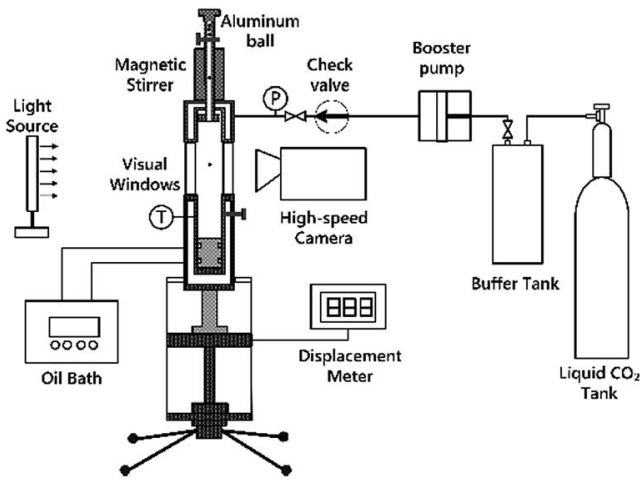

Scheme 2 Experimental device for cloud point and viscosity measurements.

$0.24 \mathrm{~g}$ AIBN. The reaction was carried out at $65{ }^{\circ} \mathrm{C}$ for 60 hours under an oil bath. After cooling, the reaction mixture was dissolved in 1,1,2-trifluorotriochloroethane, then precipitated with methanol, washed and finally dried in vacuum oven. The copolymers synthesized were named PHFDA- $x$ St and the ' $x$ ' represents the molar ratio of styrene. The four copolymers used herein were PHFDA-0.219St, PHFDA-0.299St, PHFDA-0.501St and PHFDA-0.702St, respectively.

The copolymer sample was dissolved in 1,1,2-trifluorotrichloroethane and stirred into homogeneous. Ubbelohde viscometer was used to measure the intrinsic viscosity at $25{ }^{\circ} \mathrm{C}$ to reflect the molecular weight. ${ }^{7}$

Bruker-400 $\mathrm{MHz}$ NMR was used to record the ${ }^{1} \mathrm{H}$ NMR spectrum $^{33,34}$ of the mixture of copolymer with 1,1,2-trifluorotrichloroethane in a $5 \mathrm{~mm}$ sample tube at a resonant frequency of $400 \mathrm{MHz}$. The spectra run three times and the average was used to obtain the styrene content by investigating the peak position and intensity in the spectrum.

The $10 \mathrm{wt} \%$ solution of copolymer sample with 1,1,2-trifluorotriochloroethane was used to prepare a polymer film. Krishna DSAHT high temperature contact angle meter was used to measure the contact angles of water and $n$-hexadecane on the copolymer ${ }^{32}$ film at $25^{\circ} \mathrm{C}$. The measurements were repeated five times and the average value was used to calculate the surface tension of the copolymer by Owens two-liquid method. ${ }^{35-37}$

\section{Cloud point and viscosity measurements}

The experiments of cloud point measurement and thickening capability evaluation for the four copolymers in $\mathrm{SC}-\mathrm{CO}_{2}$ were conducted by using the device as shown in Scheme 2. The aluminium ball could be placed into the kettle by adjusting the 
Table 1 The systems simulated by molecular dynamics

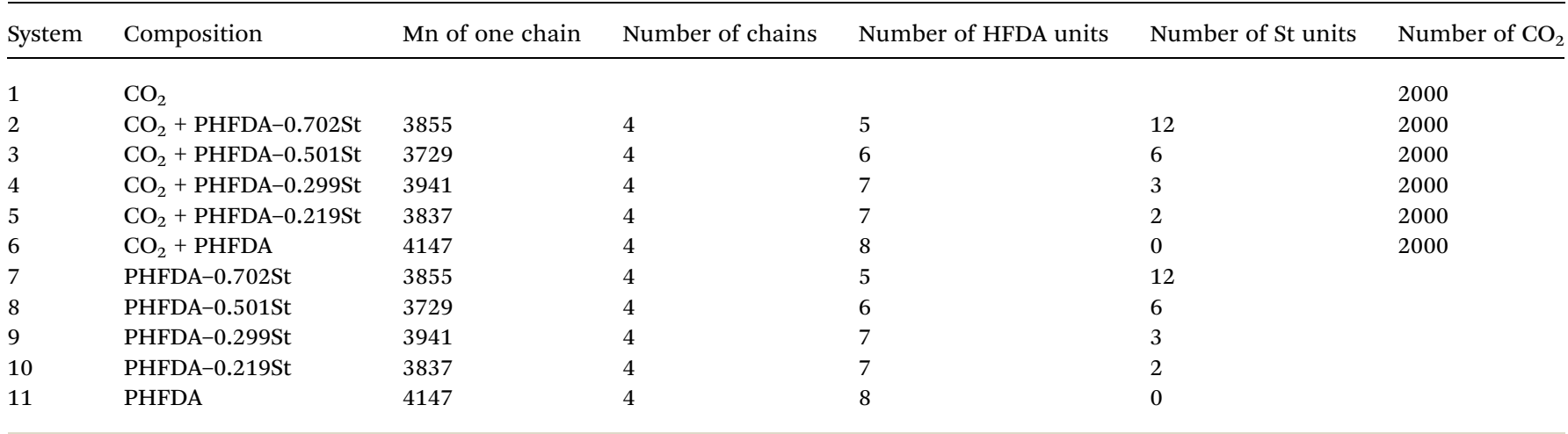

cuff of the pitching device. Olympus I-TR high-speed camera was used to shoot the progress of aluminium ball through the window by 2000 frames per second. After the temperature of polymer- $\mathrm{CO}_{2}$ mixture in the high pressure visual unit reached to the desired value, piston position was changed to allow the pressure reach the required value. Then the mixture was stirred for 30 minutes using the magnetic stirrer. Under constant temperature, the position of piston was changed slowly to increase the volume of the high pressure visual unit, so that the pressure decreased until the phase change formed. The pressure at which the phase change occurred was the cloud point pressure. ${ }^{38-41}$ The cloud point pressure was determined by repeating the three measurements.

Viscosity is calculated by eqn $(1)^{\mathbf{4 2 - 5 2}}$

$$
\eta=\frac{t\left(1-\rho_{\mathrm{l}} / \rho_{\mathrm{s}}\right)}{A\left[1+2 \alpha\left(T-T_{\mathrm{r}}\right)\right]\left[1-2 \beta\left(p-p_{\mathrm{r}}\right)\right]}
$$

where $\alpha$ and $\beta$ are the linear thermal expansion coefficient and the compression coefficient of the material used, $T_{\mathrm{r}}$ and $p_{\mathrm{r}}$ are the reference temperature and pressure, $\rho_{\mathrm{l}}$ and $\rho_{\mathrm{s}}$ are the density of the solution and aluminium ball respectively, $t$ is the drop time of aluminium ball, and $A$ is the instrument constant obtained from the regression of the experimental data as a function of $t\left(1-\rho_{1} / \rho_{\mathrm{s}}\right)$ in units of $\mathrm{mPa}^{-1}$. Viscosity measurements were repeated five times and the average value was used for the calculation.

The relative viscosity $\eta_{\mathrm{R}}$ which represents the ratio of the $\mathrm{CO}_{2}$-polymer mixture viscosity to $\mathrm{CO}_{2}$ viscosity measured under the same temperature and pressure was obtained according to the eqn (2) to evaluate the thickening capability of the copolymer. $^{7}$ It was observed that the greater the $\eta_{\mathrm{R}}$, the better thickening capability.

$$
\eta_{\mathrm{R}}=\eta_{\mathrm{mix}} / \eta_{\mathrm{CO}_{2}}
$$

where $\eta_{\text {mix }}$ is the viscosity of the $\mathrm{CO}_{2}$-polymer mixture, $\eta_{\mathrm{CO}_{2}}$ is the viscosity of $\mathrm{CO}_{2}$.

\section{Molecular dynamics simulation}

The Material Studio (MS) package was used to simulate the systems of $\mathrm{CO}_{2}$, polymers and polymer- $\mathrm{CO}_{2}$. All the force field parameters of $\mathrm{CO}_{2}$ and polymers were determined by the
COMPASS force field. ${ }^{53}$ The constructed molecules of $\mathrm{CO}_{2}$ and polymer chains were optimized by the Smart Minimizer in the Discover module of MS. Five-cycle annealing calculations from 300 to $500 \mathrm{~K}$ in the Forcite module were carried out to delay the systems effectively. ${ }^{17,54}$ The MD simulation process was done in a run time of $2 \mathrm{~ns}$ with a time step of 1 fs by using the NPT ensemble at $308.2 \mathrm{~K}$ and $25 \mathrm{MPa}$. The temperature was controlled by the Andersen method ${ }^{55}$ and the pressure was controlled by the Berendsen method. ${ }^{56}$ The Lennard-Jones 9-6 potential was used to perform the van der Waals interaction; meanwhile, the electrostatic interaction was examined by the coulombic term. The last 500 ps were used for the analysis.

Three kinds of systems were simulated by MD, respectively, the system with 2000 molecules of $\mathrm{CO}_{2}$, the system with four copolymer chains, and the polymer- $\mathrm{CO}_{2}$ system with four polymer chains and 2000 molecules of $\mathrm{CO}_{2}$. Considering the effect of molecular weight of the copolymer on the thermodynamic properties and the accuracy of the simulation results together, ${ }^{57,58}$ the PHFDA chain consisted of 10 HFDA repeating units, the PHFDA-0.219St chain consisted of 2 St repeating units and 7 HFDA repeat units, the PHFDA-0.299St chain consisted of 3 St repeating units and 7 HFDA repeating units, the PHFDA-0.501St chain consisted of 6 St repeating units and 6 HFDA repeating units, and the PHFDA-0.702St chain consisted of 12 St repeating units and 5 HFDA repeating units, to ensure that the molecular weights of different polymer chains are close to one another. The different systems of the simulation were shown in Table 1.

\section{Results and discussion}

The composition, intrinsic viscosity and surface tension measurement results of the four copolymers and PHFDA samples synthesized in this paper were shown in Table 2.

\section{Solubility of copolymers in SC-CO}

Fig. 1 showed the cloud point pressures of the five polymers in $\mathrm{SC}-\mathrm{CO}_{2}$ at $308.2 \mathrm{~K}$ with mass concentration (a) and the styrene molar ratio at $1 \mathrm{wt} \%$ of polymer (b), respectively. When the molar ratio of styrene reaches $70.2 \%$, the maximum mass concentration of this copolymer dissolved in $\mathrm{CO}_{2}$ was $1 \%$ at the pressure of $30 \mathrm{MPa}$. As shown in Fig. 1(a), the cloud point 

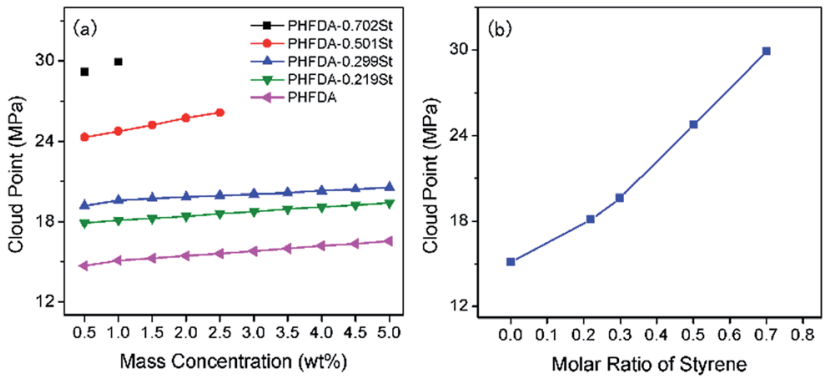

Fig. 1 Cloud point pressures of the five polymers in $\mathrm{SC}-\mathrm{CO}_{2}$ at $308.2 \mathrm{~K}$ versus mass concentration (a) and the styrene molar ratio at $1 \mathrm{wt} \%$ of polymer (b).

pressures of the five polymers in $\mathrm{SC}-\mathrm{CO}_{2}$ increased with increase of mass concentration. The differences of intrinsic viscosity which reflects the molecular weight of polymer between the five polymer samples was small as shown in Table 2, the effect of molecular weight on cloud point pressure can be ignored. So the data in Fig. 1(a) also reflected the influence of styrene molar ratio, as shown in Fig. 1(b). With the increase in the molar ratio of styrene, the cloud pressure of the copolymer in $\mathrm{SC}-\mathrm{CO}_{2}$ increased rapidly. It could be inferred that the introduction of styrene into PHFDA may be unfavourable to the solubility of the polymer in $\mathrm{SC}-\mathrm{CO}_{2}$.

In $\mathrm{CO}_{2}$-polymer system, the strong polymer- $\mathrm{CO}_{2}$ interaction is prerequisite for the polymer to be dissolved in $\mathrm{CO}_{2}$. The strength of the intermolecular interactions could be characterized by intermolecular interaction energy. The greater the absolute value of the polymer- $\mathrm{CO}_{2}$ interaction energy, the greater the $\mathrm{CO}_{2}$-philicity of the polymer. In order to compare the effect of the introduction of styrene on the $\mathrm{CO}_{2}$-philicity of

Table 2 Composition, intrinsic viscosity and surface tension measurement results of PHFDA-xSt

\begin{tabular}{llll}
\hline Polymer & $\begin{array}{l}\text { Content of styrene } \\
(\mathrm{mol} \%)\end{array}$ & $\begin{array}{l}\text { Intrinsic viscosity } \\
\left(\mathrm{g} \mathrm{mL}^{-1}\right)\end{array}$ & $\begin{array}{l}\gamma \\
\left(\mathrm{mN} \mathrm{m}^{-1}\right)\end{array}$ \\
\hline PHFDA-0.702St & 70.2 & 166.7 & 35 \\
PHFDA-0.501St & 50.1 & 159.3 & 32 \\
PHFDA-0.299St & 29.9 & 161.5 & 29 \\
PHFDA-0.219St & 21.9 & 154.5 & 28 \\
PHFDA & 0 & 168.6 & 26
\end{tabular}

Table 3 Interaction energy between polymer chains and $\mathrm{CO}_{2}$ at 308.2

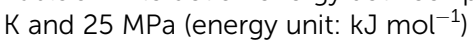

\begin{tabular}{lllll}
\hline System & $E_{\text {chain- } \mathrm{CO}_{2}}$ & $E_{\text {chain }}$ & $E_{\mathrm{CO}_{2}}$ & $E_{\text {inter }}$ \\
\hline PHFDA $+\mathrm{CO}_{2}$ & -3666.75 & -1137.35 & -1820.52 & -708.88 \\
PHFDA-0.219St $+\mathrm{CO}_{2}$ & -3296.59 & -850.28 & -1848.62 & -597.69 \\
PHFDA-0.299St $+\mathrm{CO}_{2}$ & -3165.67 & -724.84 & -1866.61 & -574.22 \\
PHFDA-0.501St $+\mathrm{CO}_{2}$ & -2713.58 & -338.47 & -1853.51 & -521.60 \\
PHFDA-0.702St $+\mathrm{CO}_{2}$ & -2533.58 & -114.60 & -1939.61 & -479.37
\end{tabular}

copolymers quantitatively, the interaction energies between polymer chains and $\mathrm{CO}_{2}$ of systems $2-5$ in Table 1 were examined with the eqn (3) ${ }^{17}$

$$
E_{\text {inter }}=-E_{\text {binding }}=E_{\text {chain }-\mathrm{CO}_{2}}-\left(E_{\text {chain }}+E_{\mathrm{CO}_{2}}\right)
$$

where $E_{\text {chain-CO }}$ is the total energy of $\mathrm{CO}_{2}$ and polymer chains, $E_{\mathrm{CO}_{2}}$ is the energy of $\mathrm{CO}_{2}, E_{\text {chain }}$ is the energy of the polymer chains and $E_{\text {inter }}$ is the polymer- $\mathrm{CO}_{2}$ interaction energy.

The results were shown in Table 3. The interaction energy of PHFDA with $\mathrm{CO}_{2}$ was significantly larger than those of the four copolymers. With the increase in styrene content of the copolymers, the absolute value of the interaction energy of the copolymers with $\mathrm{CO}_{2}$ became smaller. This indicated that the introduction of styrene into PHFDA reduced the intermolecular interaction strength of polymer- $\mathrm{CO}_{2}$, and the debilitated polymer- $\mathrm{CO}_{2}$ interaction decreased the $\mathrm{CO}_{2}$-philicity of the copolymers.

The solubility of polymer in $\mathrm{CO}_{2}$ does not only depend on the polymer- $\mathrm{CO}_{2}$ interaction, but also is related to the polymerpolymer interaction. The high solubility of polymer in $\mathrm{CO}_{2}$ requires strong polymer- $\mathrm{CO}_{2}$ interaction, and weak polymerpolymer interaction which could be described by the low surface tension. ${ }^{32,33}$ The surface tension of the polymer is related to its Cohesive Energy Density (CED) and solubility parameter. The CED and solubility parameter describe the interactive strength of polymer-polymer, which is consistent with the trend of the intermolecular interactions. Previous studies have shown that polymers with higher solubility in $\mathrm{CO}_{2}$ tend to show lower surface tension and CED. ${ }^{59}$ The low surface tension is favourable to the solvation of the polymer in $\mathrm{SC}-\mathrm{CO}_{2}$ and improves thermodynamic stability of the mixture. According to the similarity principle of solubility parameter, the smaller the solubility parameter difference $|\Delta \delta|$ between the polymer and the $\mathrm{CO}_{2}$, the better the miscibility of the polymer with $\mathrm{CO}_{2}$. The CED and solubility parameters of systems 1 and 7-11 in Table 1 obtained by the MD simulation were shown in Table 4. The $\delta$ of $\mathrm{CO}_{2}$ obtained by MD simulation at $25 \mathrm{MPa}$ and $308.2 \mathrm{~K}$ was 14.02 , which is slightly lower than the result of Ohashi $^{60}$ (14.3 at $20 \mathrm{MPa}$ and $318 \mathrm{~K}$ ) and higher than that of $\mathrm{Liu}^{17}$ (13.15 at $20 \mathrm{MP}$ and $298 \mathrm{~K}$ ). The solubility parameter of PHFDA was closest to $\mathrm{CO}_{2}$ and its cloud point was also the lowest among the five polymers. With the increase in the molar

Table 4 CED and solubility parameter values of the five polymers and $\mathrm{CO}_{2}$ at $308.2 \mathrm{~K}$ and $25 \mathrm{MPa}^{a}$

\begin{tabular}{lllll}
\hline System & $\begin{array}{l}\text { Density } \\
\left(\mathrm{g} \mathrm{cm}^{-3}\right)\end{array}$ & $\begin{array}{l}e_{\mathrm{coh}} \\
\left(\mathrm{J} \mathrm{m}^{-3}\right)\end{array}$ & $\begin{array}{l}\delta \\
\left(\left(\mathrm{J} \mathrm{cm}^{-3}\right)\right)^{1 / 2}\end{array}$ & $\begin{array}{l}|\Delta \delta| \\
\left(\left(\mathrm{J} \mathrm{cm}^{-3}\right)\right)^{1 / 2}\end{array}$ \\
\hline PHFDA & 1.69 & $2.15 \times 10^{8}$ & 14.67 & 0.65 \\
PHFDA-0.219St & 1.64 & $2.21 \times 10^{8}$ & 14.88 & 0.86 \\
PHFDA-0.299St & 1.62 & $2.24 \times 10^{8}$ & 14.97 & 0.95 \\
PHFDA-0.501St & 1.53 & $2.34 \times 10^{8}$ & 15.30 & 1.28 \\
PHFDA-0.702St & 1.40 & $2.43 \times 10^{8}$ & 15.59 & 1.57 \\
$\mathrm{CO}_{2}$ & 0.909 & $1.97 \times 10^{8}$ & 14.02 & 0 \\
${ }^{a}$ Notice: $|\Delta \delta|=\left|\delta_{\text {polymer }}-\delta_{\mathrm{co}_{2}}\right|$. & &
\end{tabular}



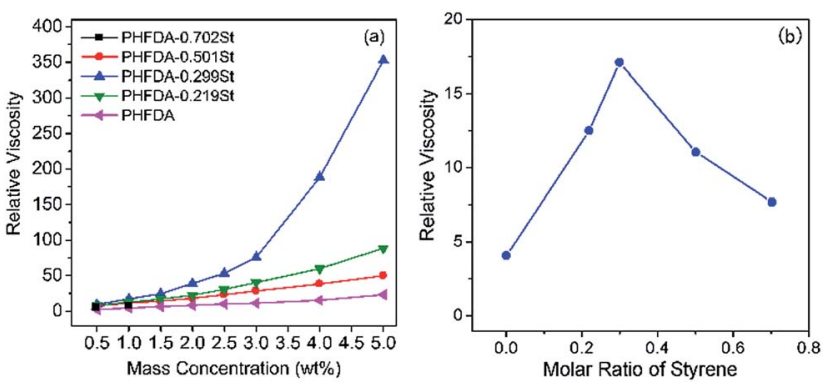

Fig. 2 Relative viscosities of the five polymers in $\mathrm{SC}-\mathrm{CO}_{2}$ at $308.2 \mathrm{~K}$ and $30 \mathrm{MPa}$ versus mass concentration (a) and the styrene molar ratio at 1 wt\% of polymer (b).

ratio of styrene in the copolymers, the CED of the copolymers increased gradually, indicating that the polymer-polymer interactions increased gradually. The results were consistent with the results of the surface tension shown in Table 1. Therefore, it can be concluded that the introduction of $\mathrm{CO}_{2}$ phobic styrene reduced the polymer- $\mathrm{CO}_{2}$ interaction and enhanced the polymer-polymer interaction, which disfavoured the dissolution of the polymer in $\mathrm{SC}-\mathrm{CO}_{2}$ and resulted in the increase of the cloud point pressures.

\section{Thickening mechanism of copolymers in $\mathrm{SC}-\mathrm{CO}_{2}$}

Fig. 2 showed the variation of relative viscosities of the polymers in $\mathrm{SC}-\mathrm{CO}_{2}$ at $308.2 \mathrm{~K}$ and $30 \mathrm{MPa}$ with mass concentration (a) and styrene molar ratio at $1 \mathrm{wt} \%$ of polymer (b), respectively. Although the introduction of styrene increased the cloud point pressure of the polymer in $\mathrm{SC}-\mathrm{CO}_{2}$, the experimental results illustrated in Fig. 2(a) indicated that all the copolymers emerged better thickening abilities than PHFDA, and PHFDA-0.299St which exhibited the best thickening effect could increase the viscosity of $\mathrm{SC}-\mathrm{CO}_{2}$ by 352 times at the concentration of $5 \mathrm{wt} \%$. As shown in Fig. 2(b), the effect of the styrene molar ratio on the thickening capability of the copolymers was not monotonically increasing or decreasing, but there existed an optimal value. It is widely known that the compounds containing phenyl groups tend to produce intermolecular association through $\pi-\pi$ stacking. So we inferred that the $\pi-\pi$ stacking between styrene groups played a key role ${ }^{7}$ in thickening $\mathrm{SC}-\mathrm{CO}_{2}$ and the styrene content of the copolymers with the best thickening capability might be about $29.9 \mathrm{~mol} \%$. The connection of the microstructures with the copolymers thickening effects was researched below using conformation snapshots and RDF obtained by MD simulation. The role of styrene and $\pi-\pi$ stacking on the thickening capability were confirmed.

The equilibrium conformations of MD simulation for the five polymer- $\mathrm{CO}_{2}$ systems were shown in Fig. 3. The $\mathrm{CO}_{2}$ molecules were hidden to highlight the polymer chains. The phenyl group atoms were marked as red, the backbone atoms were marked as black. The most pronounced intermolecular association was initiated by PHFDA-0.299St, which formed effective molecular aggregates through $\pi-\pi$ stacking ${ }^{61}$ and enhanced the viscosity of $\mathrm{SC}-\mathrm{CO}_{2}$ significantly as shown in Fig. 2(a). The lack of intermolecular association of the PHFDA chains led to slight molecular aggregate, although the chains were very stretch, indicating high miscibility with $\mathrm{SC}-\mathrm{CO}_{2}$. PHFDA-0.219St with lower styrene content showed less interchain associations. For PHFDA-0.501St and PHFDA-0.702St with higher styrene contents, the crispation of molecular chains

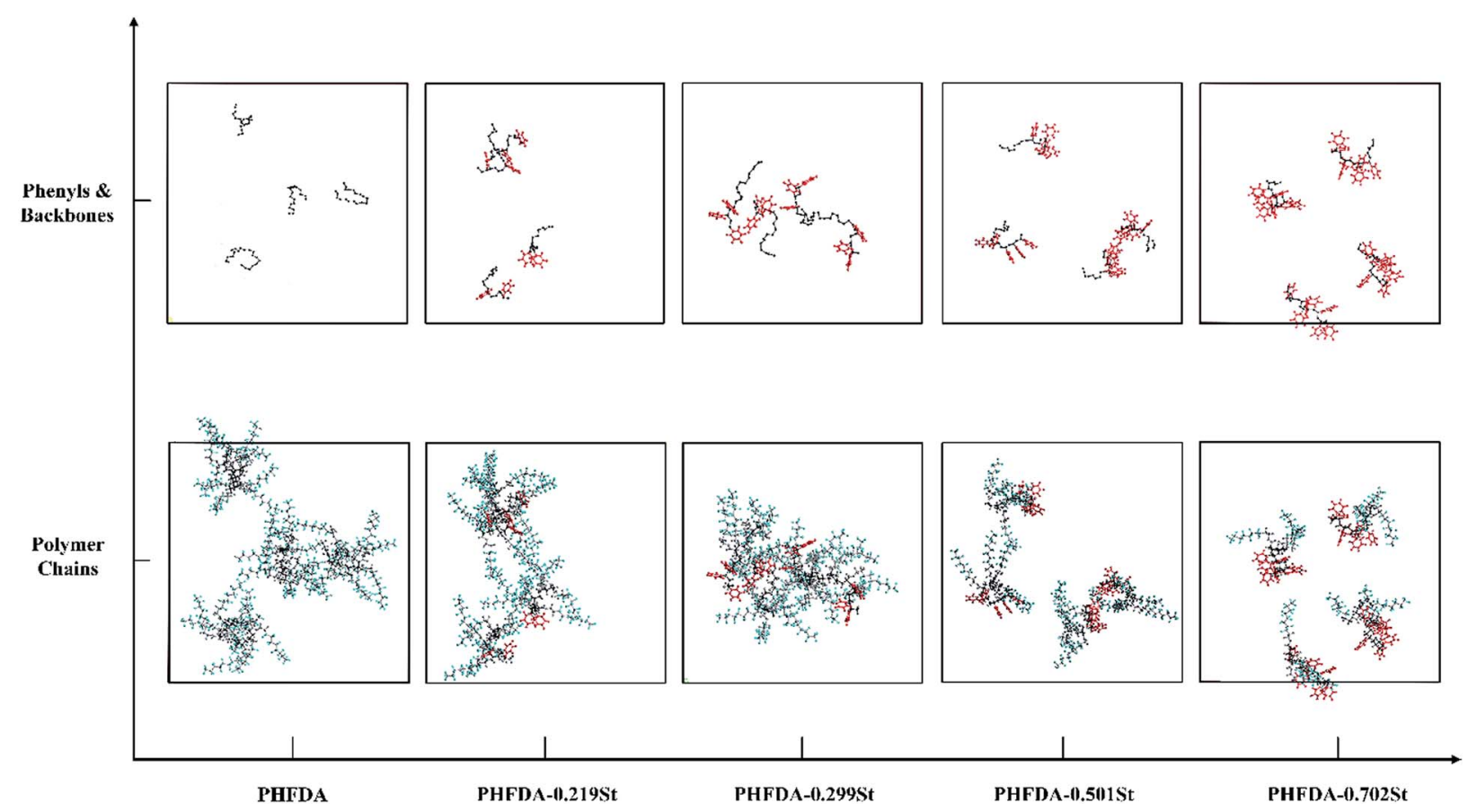

Fig. 3 Equilibrium snapshots of five $\mathrm{CO}_{2}$-polymer systems at $308.2 \mathrm{~K}$ and $25 \mathrm{MPa}$. All the $\mathrm{CO}_{2}$ molecules were deleted to highlight the polymer chains (lower) and the specific functional groups and backbones (upper). 


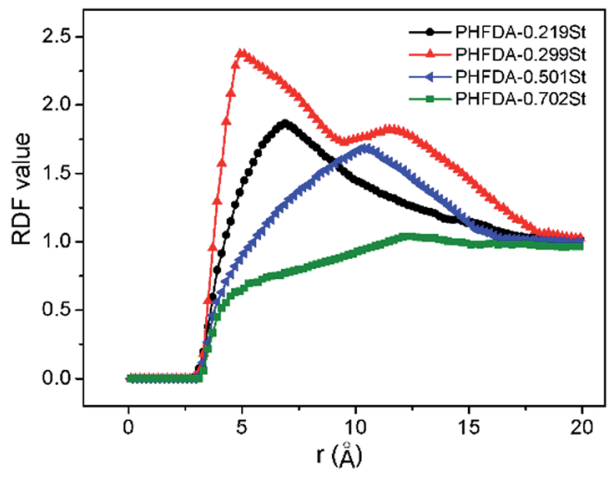

Fig. 4 Radial distribution functions of the intermolecular carboncarbon pairs of the copolymers phenyl groups.

resulted in less inter-chain $\pi-\pi$ stacking and more intra-chain $\pi-\pi$ stacking. Thickening performances of the three copolymers were not as good as PHFDA-0.299St.

To further study the microstructure of the polymer- $\mathrm{CO}_{2}$ systems, radial distribution functions (RDFs) of the systems 2-6 in Table 1 were investigated. The RDF reflects the molecular aggregation characteristics of the system..$^{62,63}$ The statistical results for $\mathrm{C}-\mathrm{C}$ pairs of the phenyl groups are shown in Fig. 4. The values of $\mathrm{RDF}$ of the four copolymer- $\mathrm{CO}_{2}$ systems increased from the value of zero at about $2.9 \AA$, which indicated that the intermolecular interactions of the copolymer chains was dominated by van der Waals. The RDF curve peak value of PHFDA-0.299St was the highest and also consistent with the equilibrium conformations in Fig. 3. The strongest peak appeared at the distance of $4.9 \AA$ which is the most feasible distance between $\mathrm{C}-\mathrm{C}$ of phenyl groups. The RDF curve peak values of PHFDA-0.219St and PHFDA-0.501St were relatively low and appeared at the farther distances of $6.9 \AA$ and $10.3 \AA$. The above results were in agreement with the equilibrium conformations and experimental results of thickening effect evaluation.

The ideal thickening agents should not only exhibit high solubility but also have the capability to enhance the viscosity significantly through intermolecular association in supercritical $\mathrm{CO}_{2}$. For the St-HFDA copolymers, the $\mathrm{CO}_{2}$-philic HFDA group helps to improve the solubility while the $\mathrm{CO}_{2}$-phobic $\mathrm{St}$ group contributes to the thickening capability for $\mathrm{SC}_{-} \mathrm{CO}_{2}$. The $\pi-\pi$ stacking of styrene groups played the major role in thickening $\mathrm{SC}-\mathrm{CO}_{2}$ by allowing the copolymer chains to aggregate effectively. The styrene content of the copolymers should be optimized to achieve a balance between solubility and thickening capability in $\mathrm{SC}-\mathrm{CO}_{2}$, and ensure the dissolution and optimum thickening capability of the copolymer in $\mathrm{SC}^{-\mathrm{CO}_{2}}$.

\section{Conclusions}

In this paper, the optimum composition of St-HFDA copolymer with the highest thickening capability in $\mathrm{SC}-\mathrm{CO}_{2}$ was obtained. The influence of the intermolecular interactions of copolymer$\mathrm{CO}_{2}$ and copolymer-copolymer on the solubility and thickening capability of copolymers in $\mathrm{SC}-\mathrm{CO}_{2}$ were examined. The he subtle relationships that exist among different group contents of the copolymers and intermolecular interactions were evaluated. This work provided a meaningful strategy for studying the solubility and thickening mechanism of the copolymers in SC$\mathrm{CO}_{2}$ by combining MD simulation and experiment, which was instructive to the molecular design of $\mathrm{SC}-\mathrm{CO}_{2}$ thickening agents. Microcosmic understanding of the intermolecular interactions in $\mathrm{CO}_{2}$-polymer systems can provide guidance for the design and optimization of polymer thickeners. It was found that:

(1) The solubility of the St-HFDA copolymer in $\mathrm{SC}^{-\mathrm{CO}_{2}}$ decreased with the increase in styrene content. The existence of styrene weakened the $\mathrm{CO}_{2}$-philicity of the copolymer by reducing the polymer- $\mathrm{CO}_{2}$ interaction and increasing polymerpolymer interaction.

(2) According to the MD simulation results, the $\pi-\pi$ stacking between the styrene groups enlarged the copolymer-copolymer interactions and promoted the formation of intermolecular crosslinks effectively. The optimum styrene molar ratio was about $29.9 \%$ for the copolymer thickening capability.

(3) The contents of the $\mathrm{CO}_{2}$-philic HFDA group and the $\mathrm{CO}_{2}$ phobic St group of the St-HFDA copolymer should be optimized to provide enough polymer- $\mathrm{CO}_{2}$ interaction and moderate polymer-polymer interaction, which allowed the copolymer to achieve optimum thickening capability in the premise of dissolved in $\mathrm{SC}-\mathrm{CO}_{2}$.

\section{Conflict of interest}

The authors declare no competing financial interests.

\section{Acknowledgements}

The authors acknowledge the support from the Key Program of National Natural Science Foundation of China (No. U1262202) and the National Key Basic Research and Development Program of China (973 Program, No. 2015CB251200).

\section{References}

1 S. Jikich, J. Pet. Technol., 2012, 64(7), 28-31.

2 L. Hou, B. Sun, X. Geng, T. Jiang and Z. Wang, J. Supercrit. Fluids, 2017, 120, 173-180.

3 L. Hou, B. Sun, Z. Wang and Q. Li, J. Supercrit. Fluids, 2015, 100, 121-128.

4 J. Xu, A. Wlaschin and R. M. Enick, SPE J., 2003, 8(2), 85-91. 5 J. P. Heller, D. K. Dandge, R. J. Card and L. G. Donaruma, $S P E$ J., 1985, 25(5), 679-686.

6 X. Sun, Z. Wang, B. Sun and W. Wang, J. Nat. Gas Sci. Eng., 2016, 33, 1390-1401.

7 Z. Huang, C. Shi, J. Xu, S. Kilic, R. M. Enick and E. J. Beckman, Macromolecules, 2000, 33(15), 5437-5442.

8 L. L. Williams, J. B. Rubin and H. W. Edwards, Ind. Eng. Chem. Res., 2004, 43(16), 4967-4972.

9 R. D. Lousenberg and M. S. Shoichet, Macromolecules, 2000, 33(5), 1682-1685.

10 F. R. Ancisa, J. Phys. Chem., 1954, 58, 1099-1114. 
11 Z. Guan, J. R. Combes, Y. Z. Menceloglu and J. M. Desimone, Macromolecules, 1993, 26, 2663-2669.

12 R. M. Enick, D. Olsen, J. Ammer and W. Schuller, presented in part at the Eighteenth SPE Improved Oil Recovery Symposium, Tulsa, Oklahoma, USA, April 2012.

13 J. M. Desimone, Z. Guan and C. S. Elsbernd, Science, 1992, 257, 945-947.

14 C. L. Bray, B. Tan, S. Higgins and A. I. Cooper, Macromolecules, 2010, 43(22), 9426-9433.

15 D. Denney, J. Petro. Technol., 2013, 65(1), 89-91.

16 J. H. Bae and C. A. Irani, SPE. Adv. Tech., 1993, 1(1), 166-171.

17 D. Hu, S. Sun, P. Yuan, L. Zhao and T. Liu, J. Phys. Chem. B, 2015, 119, 3194-3204.

18 S. Kilic, Y. Wang, J. K. Johnson, E. J. Beckman and R. M. Enick, Polymer, 2009, 50, 2436-2444.

19 G. Luna-Bárcenas, S. Mawson, S. Takishima, J. M. DeSimone, I. C. Sanchez and K. P. Johnston, Fluid Phase Equilib., 1998, 146, 325-337.

20 J. B. McClain, D. Londono, J. R. Combes, T. J. Romack, D. A. Canelas, D. E. Betts, G. D. Wignall, E. T. Samulski and J. M. DeSimone, Neuroradiology, 1996, 118, 917-918.

21 S. Kilic, S. Michalik, Y. Wang, J. K. Johnson, R. M. Enick and E. J. Beckman, Ind. Eng. Chem. Res., 2003, 42, 6415-6424.

22 M. J. O'Brien, R. J. Perry, M. D. Doherty, J. J. Lee, A. Dhuwe, E. J. Beckman and R. M. Enick, Energy Fuels, 2016, 30, 59905998.

23 C. Shi, Z. Huang, E. J. Beckman, R. M. Enick, S.-Y. Kim and D. P. Curran, Ind. Eng. Chem. Res., 2001, 40(3), 908-913.

24 T. Sarbu, T. J. Styranec and E. J. Beckman, Ind. Eng. Chem. Res., 2000, 39, 4678-4683.

25 T. Sarbu, T. Styranec and E. J. Beckman, Nature, 2000, 405, 165-168.

26 Y. Wang, L. Hong, D. Tapriyal, I. C. Kim, I.-H. Paik, J. M. Crosthwaite, A. D. Hamilton, M. C. Thies, E. J. Beckman, R. M. Enick and J. K. Johnson, J. Phys. Chem. B, 2009, 113, 14971-14980.

27 A. Cece, S. H. Jureller, J. L. Kerschner and K. F. Moschner, J. Phys. Chem., 1996, 100, 7435-7439.

28 B. Baradie, M. S. Shoichet, Z. Shen, M. A. McHugh, L. Hong, Y. Wang, J. K. Johnson, E. J. Beckman and R. M. Enick, Macromolecules, 2004, 37, 7799-7807.

29 P. Raveendran and S. L. Wallen, J. Am. Chem. Soc., 2002, 124, 7274-7275.

30 P. Raveendran and S. L. Wallen, J. Phys. Chem. B, 2003, 107, 1473-1477.

31 J. R. Fried and N. Hu, Polymer, 2003, 44, 4363-4372.

32 E. Girard, T. Tassaing, C. Ladaviere, J.-D. Marty and M. Destarac, Macromolecules, 2012, 45, 9674-9681.

33 E. Girard, T. Tassaing, S. Camy, J.-S. Condoret, J.-D. Marty and M. Destarac, J. Am. Chem. Soc., 2012, 134, 11920-11923.

34 H. Lee, J. W. Pack, W. Wang, K. J. Thurecht and S. M. Howdle, Macromolecules, 2010, 43, 2276-2282.

35 B. Lavi, A. Marmur and J. Bachmann, Langmuir, 2008, 24, 1918-1923.
36 Y. Tamai, T. Matsunaga and K. Horiuchi, J. Colloid Interface Sci., 1977, 60(1), 112-116.

37 K. Katoh, T. Yu, M. Yamamoto, T. Azuma and H. Fujita, J. Colloid Interface Sci., 1998, 202(1), 54-62.

38 R. M. Enick, E. J. Beckman, A. Yazdi, V. Krukonis, H. Schonemann and J. Howell, J. Supercrit. Fluids, 1998, 13, 121-126.

39 B. Tan, C. L. Bray and A. I. Cooper, Macromolecules, 2009, 42, 7945-7952.

40 H. S. Byun and T. H. Choi, J. Appl. Polym. Sci., 2002, 86, 372380.

41 Z. Wang, B. Sun, X. Sun, H. Li and J. Wang, Greenhouse Gases: Sci. Technol., 2015, 5, 1-11.

42 H. Matsuda, H. Yamamoto, K. Kurihara and K. Tochigi, Fluid Phase Equilib., 2007, 261, 434-443.

43 J. L. Sutterby, AIChE J., 1966, 12(1), 63-68.

44 C. Boned, M. Moha-Ouchane, A. Allal and M. Benseddik, Int. J. Thermophys., 1998, 19(5), 1325-1341.

45 Z. Fang, Y. Qiao, Z. Di, Y. Huo, P. Ma and S. Xia, J. Chem. Eng. Data, 2008, 53(12), 2787-2792.

46 D. Papaioannou, M. Bridakis and C. G. Panayiotou, J. Chem. Eng. Data, 1993, 38(3), 370-378.

47 J. H. Dymond, K. J. Young and J. D. Isdale, Int. J. Thermophys., 1980, 1(4), 345-373.

48 R. Malhotra, W. E. Price, L. A. Woolf and A. J. Easteal, Int. J. Thermophys., 1990, 11(5), 835-861.

49 Y. Qiao, S. Xia and P. Ma, J. Chem. Eng. Data, 2008, 53(1), 280-282.

50 Z. Fang, Y. Qiao, Z. Di, Y. Huo, P. Ma and S. Xia, J. Chem. Eng. Data, 2008, 53(12), 2787-2792.

51 Y. Qiao, Y. Ma, Y. Huo, P. Ma and S. Xia, J. Chem. Thermodyn., 2010, 42, 852-855.

52 Y. Qiao, Z. Di, Y. Ma, P. Ma and S. Xia, Chin. J. Chem. Eng., 2010, 18(3), 446-454.

53 H. Sun, J. Phys. Chem. B, 1998, 102, 7338-7364.

54 D. N. Theodorou and U. W. Suter, Macromolecules, 1986, 19, 139-154.

55 H. C. Andersen, J. Chem. Phys., 1980, 72(4), 2384-2393.

56 H. J. C. Berendsen, J. P. M. Postma, W. F. V. Gunsteren, A. Dinola and J. R. Haak, J. Chem. Phys., 1984, 81, 3684-3690.

57 D. Hu, Y. Zhang, M. Su, L. Bao, L. Zhao and T. Liu, J. Supercrit. Fluids, 2016, 118, 96-106.

58 D. Hu, S. Sun, P. Yuan, L. Zhao and T. Liu, J. Phys. Chem. B, 2015, 119, 12490-12501.

59 Y. Marcus, J. Supercrit. Fluids, 2006, 38, 7-12.

60 J. Ougiyanagi, Y. Meguro, Z. Yoshida, H. Imura and K. Ohashi, Talanta, 2003, 59, 1189-1198.

61 C. A. Hunter and J. K. M. Sanders, J. Am. Chem. Soc., 1990, 112, 5525-5534.

62 T. C. Clancy and W. L. Mattice, Macromolecules, 2001, 34, 6482-6486.

63 P. Gestoso and J. Brisson, Polymer, 2003, 44, 2321-2329. 